\title{
Against the New Metaphysics of Race David Ludwig
}

Final version published as

Ludwig, D. (2015) "Against the New Metaphysics of Race" Philosophy of

Science 82 (2): 244-265.

\begin{abstract}
The aim of this article is to develop an argument against metaphysical debates about the existence of human races. I argue that the ontology of race is underdetermined by both empirical and nonempirical evidence owing to a plurality of equally permissible candidate meanings of "race." Furthermore, I argue that this underdetermination leads to a deflationist diagnosis according to which disputes about the existence of human races are nonsubstantive verbal disputes. While this diagnosis resembles general deflationist strategies in contemporary metaphysics, I show that my argument does not presuppose controversial metametaphysical assumptions.
\end{abstract}

1. Introduction. The aim of this article is to develop an argument against metaphysical debates about the existence of human races. Controversies about the biological reality of human races have gained increasing attention in the past two decades and are dominated by the opposition between racial realists (e.g., Edwards 2003; Leroi 2005; Andreasen 2007; Sesardic 2010; Spencer 2014b) and antirealists (e.g., Appiah 2006; Zack 2007; Glasgow 2009; Maglo 2011; Hochman 2013). ${ }^{1}$ In contrast to both realists and antirealists, I want to argue that the current debate about the existence of human races is based on a confusion of metaphysical and normative classificatory issues.

In section 2 I argue that empirical evidence about human biological diversity underdetermines the ontology of race. Section 3 suggests that nonempirical evidence, such as theories of reference or conceptual analysis,

1. In the following, I focus on debates about the biological reality of races and ignore the question whether "race" refers to real social kinds (cf. Alcoff 2005; Haslanger 2012). However, it may be possible to extend my deflationist diagnosis to debates about the social reality of races; see n. 4 . 
fails to solve this problem of underdetermination owing to multiple permissible candidate meanings of "race." Finally, I argue in section 4 that the combination of empirical and nonempirical underdetermination leads to a deflationist account of "the new metaphysics of race." Philosophers who insist on a metaphysical debate about the question whether races exist end up engaging in a nonsubstantive verbal dispute.

Although my deflationist proposal shares important similarities with general deflationist accounts of ontology (e.g., Putnam 1987; Chalmers 2009; Hirsch 2011), I contend that my argument does not require controversial metaontological assumptions. Based on Sider's (2012) discussion of nonsubstantive disputes, I suggest that a deflationist account of the metaphysics of race should be accepted even under the assumption of a strong metaphysical and ontological realism. My goal is therefore to convince even passionate metaphysicians that the "new metaphysics of race" is a bad idea that is not only theoretically dubious but also in risk of obscuring the genuinely important epistemological, ethical, and political issues in scientific classification. ${ }^{2}$

2. Underdetermination through Empirical Evidence. The aim of this section is to argue that empirical evidence about human diversity is compatible with both racial realism and antirealism. More specifically, I argue for two logically independent (but often entangled) types of underdetermination. The first type of underdetermination is based on the general idea that biological ontologies are shaped by contingent explanatory interests. Biologists with different research interests find different biological patterns meaningful and therefore postulate the existence of different biological kinds. ${ }^{3}$ The second type of underdetermination is concerned not with the existence of biological kinds but with the identification of biological kinds with races. Even if we

2. Of course, one can avoid this conclusion by endorsing a more liberal notion of "metaphysics of race." I assume that metaphysicians of race are committed to the ideal of one fundamental ontology of race. This terminology follows common distinctions in contemporary metaphysics that include realists and antirealists about x (e.g., composed objects, personal identity over time, vague objects) and deflationists who reject the entire project of a "metaphysics of x." Furthermore, this terminology comes with the rhetorical benefit of being able to claim that the ontological status of race depends on normative and not metaphysical issues (cf. Mallon 2006). However, I do not want to engage in a verbal dispute about the meaning of "metaphysics of race," and one could also use a less restrictive definition. Given a sufficiently liberal definition, this article only challenges a certain type of metaphysics of race while proposing an alternative deflationist and normative metaphysics of race.

3. For the sake of simplicity, I limit myself to a discussion of biological ontologies in terms of biological kinds. However, the presentation could be extended to other biological entities, as not all philosophers accept that "race" (or "species") is a kind term (Spencer 2014a). 
postulate the same biological kinds, we can still disagree whether we should identify any of them with races.

2.1. The Interest Dependency of Biological Ontologies. Arguments for the first type of underdetermination typically start with the diversity of explanatory interests in scientific practice. In a second step, it is assumed that researchers with different explanatory interests will often find different biological patterns meaningful and therefore postulate the existence of different biological kinds. Finally, it is claimed that these differences persist even if two researchers have access to the same empirical evidence. In its most radical form, the underdetermination thesis comes with a strong pragmatist attitude that reduces natural kinds to useful kinds (cf. Kitcher 2007). However, the empirical underdetermination of biological ontologies can also be defended on the basis of more moderate proposals. For example, many philosophers of science acknowledge that biological kinds pick out empirically discovered property clusters but still insist on the constitutive importance of epistemic interests in the identification of biological kinds (e.g., Franklin-Hall, forthcoming; Slater, forthcoming). While the interest dependency of biological ontologies is traditionally illustrated in the context of the species debate, it can be easily extended to biological kinds below the species level. Given the overwhelming amount of data on genetic similarities and differences between human populations, it seems plausible that researchers with different explanatory interests will find different genetic patterns meaningful and will therefore postulate different genetic kinds.

In addition to this application of general arguments from philosophy of biology, recent debates about biogenomic races provide a more careful justification for ontological underdetermination below the species level. Most importantly, Kaplan and Winther (2012; see also Winther and Kaplan 2013) have proposed a detailed account of how different measures of genetic variation can lead to different ontologies of race. Kaplan and Winther's (2012) starting point is a discussion of the very concept of genetic variation and three common technical meanings: genetic diversity, genetic differentiation, and heterozygosity. These different accounts of genetic variation not only prove useful in different research contexts but also can be combined with different metrics that yield different data interpretations. For example, genetic diversity allows for different ways of measuring genetic variation in a population. Most obviously, genetic diversity in a population depends on both the number of alleles at a locus and the frequency of alleles in question. Given that diversity measures can differ in their sensitivity to allele frequency, there is not one metric-independent account of genetic diversity. In other words, not only does genetic variation encompass the three technical meanings of genetic diversity, genetic differentiation, and heterozygosity, but each meaning can 
be combined with a variety of metrics. Kaplan and Winther therefore conclude that "there are many metrics and meanings of 'genetic variation.' Our choice among these is conventional, and the sort of racial landscape pro- vided by one metric may be shifted, even reversed, by another" (2012, 11). For example, the fact that we can use clustering software such as STRUCTURE (Rosenberg et al. 2002) to identify continental clusters that roughly correspond to traditional racial boundaries does not prove their existence (cf. Kalinowski

2011). Instead, the tricky question is which of the countless possible clusters we should identify as legitimate biological kinds.

In a subsequent publication, Winther and Kaplan (2013) substantiate this rather abstract argument for empirical underdetermination by considering the relevance of biogenomic kinds in different research contexts. More specifically, they consider taxonomy, phylogenetics, ecology, and conservation biology as four subdisciplines that make different uses of biogenomic kinds. Different biogenomic kinds are not only the consequence of differences between these subdisciplines but also implied by different research interests within each of these subdisciplines. In the case of phylogenetics, Winther and Kaplan point out that any account of intraspecific kinds in Homo sapiens depends on "data choice; choice of models and measures; choice of tree vs. trellis topology; and getting out what you put in (i.e. using anthropological and linguistic information). The decisions made about each of these provide better explanations of why particular interlocutors choose to adopt racial realism or anti-realism than do the genomic facts to which they appeal" $(2013,68)$.

To sum up, the first type of underdetermination is based on the assumption that researchers with different explanatory interests will find different biological kinds useful in research. Kaplan and Winther specify this idea by developing an account of different measures and metrics in contemporary genetic research. For example, clustering software such as STRUCTURE makes it easy to detect new biogenomic kinds, but the real challenge is to identify kinds that are sufficiently meaningful to qualify as legitimate biological kinds. Empirical evidence underdetermines the ontological status of race, as this evaluation of the relevance of kinds requires the consideration of explanatory interests.

2.2. The Identification of Biological Kinds and Races. The first type of underdetermination suggests that different explanatory interests in scientific practice lead to different biological ontologies that postulate different kinds. However, a closer look at current debates about race also reveals a second type of empirical underdetermination that is at least logically independent from debates about the existence of biological kinds. To illustrate this point, let us assume for the sake of the argument a strong ontological realism in biology that comes with exactly one system of objective, interested- 
independent, and nonambiguous kinds that "carve nature at its joints." While this assumption would undermine the first type of underdetermination and solve any disagreement regarding the existence of biological kinds, it would not solve all disagreement regarding the existence of human races. Instead, there could still be disagreement between racial realists and antirealists regarding the question whether we should identify any of the objective, interested-independent, and nonambiguous kinds with human races.

This second type of underdetermination can be conveniently illustrated on the basis of current controversies about Rosenberg et al.'s (2002) highly influential study "Genetic Structure of Human Populations," which used STRUCTURE for a cluster analysis of the HGDP-CEPH Human Genome Diversity Cell Line Panel. On the basis of data from 52 populations, Rosenberg et al. aimed at the identification of the genetic structure of human populations at different grains of analysis. At $\mathrm{K}=5$, they identified genetic clusters that roughly match continental populations: (Africa), (Central-South Asia, Europe, Middle East), (East Asia), (Oceania), (America). Rosenberg et al.'s clusters at $\mathrm{K}=5$ roughly match traditional distinctions between races in the tradition of Blumenbach and have been endorsed as the referents of "race" by racial realists such as Edwards (2003), Sesardic (2010), and Spencer (2013).

However, Rosenberg et al.'s clusters at $\mathrm{K}=5$ are not the only potential referents of "race." First, some racial realists have suggested more finegrained racial ontologies on the basis of genetic cluster analysis. For example, Leroi argues that a sufficiently detailed analysis would allow us to "sort the world's population into 10, 100, perhaps 1000 groups" (2005, 4 ), and he uses this observation to endorse a fine-grained account of races that

includes, for example, Basques. Second, racial realists have proposed a large variety of nongenetic accounts of race, such as Andreasen's (1998) account of races as clades, Kitcher's (1999) account of races as "patterns of mating," or Hardimon's account of populations with a "distinctive pattern

of genetically transmitted phenotypic characters and that belongs to an endogamous biological lineage initiated by a geographically separated and reproductively isolated founding population" $(2012,250)$.

Finally, antirealists also propose a variety of concepts of race that imply the nonexistence of races in Homo sapiens. Hochman's (2013) account of races as subspecies provides a very attractive example of this strategy. Hochman points out that subspecies in nonhuman biology are not distinguished on the basis of genetic cluster analysis. Instead, a common method relies on Wright's fixation index $\left(\mathrm{F}_{\mathrm{ST}}\right)$, which compares genetic variation in subpopulations with genetic variation in the total population. While a species is often divided into subspecies if $\mathrm{F}_{\mathrm{ST}} \geq 0.25$, human $\mathrm{F}_{\mathrm{ST}}$ is estimated around 0.05 to 0.15 . Given this account of races as subspecies, there are no human races. 
This diversity of concepts of race clearly illustrates a second type of underdetermination. Different conceptual choices regarding "race" will have different implications regarding the ontological status of races. For example, an account of races as genetic clusters at $\mathrm{K}=5$ will give us good reason to believe that human races exist. An account of races as subspecies with $\mathrm{F}_{\mathrm{ST}} \geq 0.25$ implies that human races do not exist. Given that empirical evidence cannot force us to use the concept of race in one way or another, the ontological status of race remains underdetermined by empirical evidence.

3. Underdetermination through Nonempirical Evidence. Metaphysicians of race can respond to my presentation of empirical underdetermination by arguing that it actually illustrates the need for a philosophical discussion that looks beyond empirical evidence. Even if the debate about the ontological status of race is underdetermined by empirical evidence, it may still be resolved by nonempirical evidence. Spencer, for example, responds to Kaplan and Winther by pointing out that "even though biological theory and data do not force race onto us, it does not follow from this that it is illegitimate to read any ontology about race off of biological theory or data. The reason is because one need not restrict 'legitimate' ontological inferences from biological theory or data to ontological inferences entailed by biological theory or data" $(2013,117)$. Spencer's objection can be illustrated with both realist and antirealist arguments in current debates about the existence of human races. One common realist strategy applies "causal theories of reference" (CTR) in the tradition of Kripke and Putnam to debates about the referent of "race." The basic idea is that CTR shows that folk concepts such as "race" can refer to scientific entities such as genetic clusters or clades even if this identification requires revisions of folk accounts (e.g., Andreasen 2000). For example, the term "tiger" arguably always referred to tigers even if folk accounts of tigers include or included flawed assumptions such as biological essentialism. Instead of assuming that the folk concept "tiger" failed to refer owing to a problematic biological essentialism, it is much more plausible to argue that wrong assumptions about tigers have been corrected by modern biology. The employment of CTR illustrates why racial realists can accept empirical underdetermination and still insist on one correct answer in debates about the biological reality of race. Indeed, there may be a variety of specifications of "race" that are compatible with empirical evidence, but CTR shows that "race" refers to the real natural kinds that are identified in biological research.

In response to these considerations, racial antirealists often employ a "conceptual mismatch argument" (Glasgow 2003) according to which an account of race in terms of genetic clusters or clades would require revisions of the concept "race" that are so substantial that we simply wouldn't talk 
about races anymore. Consider the following example of a conceptual mismatch that illustrates the shortcomings of an overly liberal application of CTR: in the Renaissance, many cabinets of curiosity included "unicorn horns," which were in fact narwhal horns. Of course, we could come up with a "scientific confirmation" of the existence of unicorns by identifying unicorns with Monodon monoceros, that is, narwhals. The obvious problem with this scientific confirmation of the existence of unicorns is that this account of unicorns has little in common with what we actually mean by "unicorn." Clearly, it is less misleading to insist on the existence of Mon- odon monoceros but to reject the existence of unicorns. In the same sense, an antirealist can suggest that it would be misleading to identify races with clades or genetic clusters. In both cases the mistake is not empirical but conceptual, as the person who insists on the existence of unicorns/races by referring to narwhals/genetic clusters simply misunderstands the meaning of "unicorn"/"race." Of course, one could reform the concepts "unicorn" and "race" in a way that they end up referring to narwhals and genetic clus- ters. But as long as we use the words in their usual meaning, the existence claims are false.

Arguably neither the realist analogy to tigers nor the antirealist analogy to unicorns is entirely fair. Clearly, the relationship between "race" and potential referents such as Rosenberg et al.'s genetic clusters at $K=5$ or Andreasen's clades is less straightforward than in the case of species such as "tiger." For example, it requires a revision not only of essentialism but also of the common assumption that visible traits such as skin color are markers of important biological differences (Glasgow 2009). At the same time, none of these revisions are as implausible as a revision of "unicorn" that ensures reference to narwhals. In the case of unicorns and narwhals, we only have one relevant morphological feature (the horn), while the identification of races with scientific entities such as genetic clusters at $\mathrm{K}=5$ appears to be more meaningful by reflecting shared geographical ancestry.

3.1. What Are Allowable Revisions of "Race"? The identification of human races with entities such as genetic clusters at $K=5$ arguably re- quires more revisions than an identification of tigers with Panthera tigris and less revisions than an identification of unicorns with Monodon mono- ceros. At this point, the crucial question becomes how we can distinguish between legitimate revisions that entail successful reference and illegitimate revisions that entail failed reference. Glasgow (2003, 463) clearly admits this by stating, "The question, again, is: How much revision is allowable?" However, this brings both realist and antirealist metaphysicians of race to the uncomfortable position of having to argue not only that there are clear criteria that separate allowable and nonallowable revisions but also that only their own account of "race" satisfies these criteria. Without these as- 
sumptions, we would not be able to identify one fundamental account of "race" and would therefore end up with a plurality of equally allowable ontologies of race.

Any attempt to justify a substantive metaphysics of race will therefore have to engage with the vast number of possible specifications of "race" in terms of (1) genetic clusters at $K=5$ in the sense of Spencer (2014a); (2) genetic clusters at a finer grain of analysis in the sense of Leroi (2005); (3) human ecotypes in the sense of Pigliucci (2013); (4) human subspecies in the sense of Hochman (2013); (5) human groups with visible traits, common ancestry, and geographic origin in the sense of Hardimon (2003); (6) human groups with visible traits that correspond to meaningful biological differences in the sense of Glasgow (2009); (7) human groups with relevant cognitive differences in the sense of Feldman and Lewontin (2008); (8) human groups with essential intrinsic properties in the sense of Appiah (2006); and so on. ${ }^{4}$

Any philosopher who endorses one specific proposal faces the following choice. On the one hand, she can restrict herself to the moderate claim of proposing an allowable specification of "race" without rejecting the availability of other allowable specifications. While this is certainly a reasonable strategy, it is tantamount to the rejection of a substantive metaphysics of race. If there is a plurality of equally allowable specifications of "race," there is also a plurality of equally allowable ontologies of race. One specification may still be preferable in the light of certain pragmatic considerations, but that does not help philosophers who aim at a metaphysical decision of debates about the reality of human races. On the other hand, philosophers of race can also insist on the ambitious claim that there is exactly one fundamental specification of "race" that leads to a nonambiguous ontology of race. While this strategy would justify the ideal of a substantive metaphysics of race, the diversity of suggested specifications of "race" can certainly raise doubts about its viability.

Although I will argue that we should reject this ambitious second strategy, metaphysicians of race can attempt to specify the meaning of "race" in

4. Although I have limited my discussion to debates about the biological reality of races, one could add nonbiological social kinds to this list of potential referents. For example, Haslanger $(2012,278)$ has suggested understanding races as "racialized groups" whose "members are socially positioned as subordinate or privileged along some dimension." Furthermore, one may argue that my worries about the ambiguity of "race" extend to the question whether the concept refers to a biological or social kind. For example, Saul $(2006,130)$ has argued that "race" in ordinary language is too confused to disentangle a biological and social meaning. However, much more would have to be said to justify this skepticism in debates about social kinds - especially in the light of Haslanger's more recent discussion of "race" in terms of an externalist "Jazz model of meaning" (2010; cf. Diaz-Leon 2012). 
a way that clarifies ontological implications. The first step toward such a specification is arguably a distinction between commonsense and scientific uses of "race." While commonsense and scientific uses of "race" cannot be completely separated (Gannett 2010; Morning 2011), a distinction is still of- ten helpful to avoid confusions in debates about race. However, any spec- ification will face the mentioned dilemma: On the one hand, we can simply choose to specify "race" by focusing on commonsense or scientific uses of "race." While this is certainly helpful in clarifying the debate, it makes realist and antirealist positions compatible with alternative accounts that choose to specify "race" in a different way. On the other hand, one can make the more ambitious claim that one way of specifying "race" is more relevant than others. For example, the first premise of Glasgow's mismatch argument seems to aim at this stronger claim: "For the race debate, the relevant meta- physical question is whether the commonsense concept of race picks out something real" (Glasgow 2010, 56).

Why should we accept this premise instead of insisting that scientific uses of "race" are more or equally relevant? Glasgow attempts to justify his assumption with analogies such as "schizophrenia," where the commonsense concept of schizophrenia often refers to dissociative identity disorder (ICD-10 F44.8), while the current scientific use refers to a different mental disorder (ICD-10 F20). While this example illustrates that it is often important to distinguish different meanings of a term, it does little in supporting Glasgow's claim of the priority of the commonsense concept in the metaphysics of race. Glasgow imagines a dispute about the question whether George, who suffers from dissociative identity disorder, is schizophrenic. Arguably, this question does not have only one correct answer. Even in everyday contexts, laypeople with different levels of scientific literacy will interpret this question in different ways: "schizophrenic" is often used (1) in a very general way that refers to some form of cognitive and behavioral dissonance but not to a mental disorder at all, (2) to refer to dissociative identity disorder, and (3) to refer to schizophrenia in the current medical sense. As long as we don't specify the context, a general question whether George is schizophrenic simply does not have only one correct answer, and philosophers who want to engage in a "metaphysics of mental disorders" need to be careful to avoid a pointless verbal dispute regarding the question whether George is really schizophrenic.

Contrary to Glasgow's intentions, the analogy to schizophrenia therefore seems to cast doubt on metaphysical debates about race: in the same sense as the unqualified question whether George is schizophrenic does not have only one correct answer, the unqualified question whether races exist arguably does not have only one correct answer either. Glasgow avoids this conclusion in his thought experiment of George by specifying the context in 
a way that "two laypeople [are] trying to sort out whether he has multiple personalities" (2010, 58). This specification, however, turns Glasgow's ar- gument into a petitio principii, if it is supposed to support the priority of commonsense concepts. Indeed, in sufficiently specified contexts, the pri- ority of one account of "schizophrenia" (or "race") is uncontroversial, but the problem with the current metaphysics of race is precisely that the con- text does not seem to be sufficiently specified.

The general problem therefore remains unsolved. The meaning of "race" can be specified in different ways in different contexts. Both realist and antirealist metaphysicians of race need to show that there is one prior way of specifying "race," but it remains unclear how this is possible given the diversity of relevant contexts in current debates about the reality of human races. One may object that the current academic debate about the existence of human races provides a sufficient specification, as numerous philosophers, including Kitcher (1999), Glasgow (2003), Appiah (2006), and Spencer (2014a), have been very clear about their focus on the commonsense concept of race. However, other philosophers, including Boxill (2004), Hacking (2005), Maglo (2011), Hochman (2013), and Pigliucci (2013), focus on scientific uses of "race." Furthermore, the context also depends on how we draw the boundaries of current debates about the existence of races. If we focus more narrowly on recent philosophical publications, we may find a majority being concerned with the commonsense concept of race. If we also include the vast literature on this issue in the life sciences, we will find a majority being concerned with scientific concepts of race. One way or another, we will find a large diversity of uses that casts doubt on the idea of exactly one relevant specification and suggests a variety of relevant specifications that lead to different answers regarding the ontological status of race.

This situation suggests a minimal deflationism regarding the metaphysics of race that allows at least two legitimate ways of interpreting the question whether races exist in the sense of commonsense and scientific concepts. This position is deflationist because it implies that (anti)realist positions that rely on a commonsense concept of race are entirely compatible with positions that have opposing ontological consequences but rely on a scientific concept of race. For example, the commonsense concept of race may refer to genetic clusters, while a scientific concept of race refers to subspecies. In this case, human races ordinary $_{\text {would exist, while human races }}$ scientific would not exist. Or, the commonsense concept may fail to refer owing to flawed morphological criteria, while a scientific concept of race refers to ecotypes. In this case, human races ordinary $_{\text {w }}$ would not exist, while human races scientific $_{\text {. }}$ would exist. At the same time, this deflationism is minimal because it allows the assumption that there is only one eligible way of specifying race ordinary and race $_{\text {scientific }}$. 
3.2. Specifying Scientific and Commonsense Concepts of Race. Although I have suggested a minimal deflationism in the previous section, there are good reasons to extend this skeptical attitude to debates about

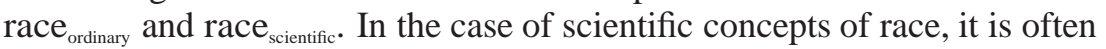
noted that race talk has become rather uncommon in most areas of scientific practice (Templeton 1998) and that the remaining use of "race" in science is quite heterogeneous. For example, I have already mentioned that there are no human races given standard criteria for subspecies in biological systematics such as $F_{S T} \geq 0.25$ (cf. Templeton 2013). However, there are also more liberal uses of "race," such as the identification of races with ecotypes in the sense of Pigliucci and Kaplan (2003; see also Pigliucci 2013). Furthermore, the disappearance of races from large parts of anthropological research suggests that anthropologists often adopt a notion of race that requires morphological and maybe even cognitive differences that make the existence of races wildly implausible (American Anthropological Association 1998). Finally, the resurgence of "race" in biomedical research suggests that many researchers use "race" in ways that match neither traditional subspecies nor ecotypes (cf. Root 2003; Torres and Kittles 2007; Gissis 2008). Unless we assume that classifications in all disciplines of the life sciences must be taxonomically relevant for biological systematics, the problem of multiple specifications

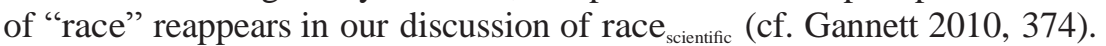
Given that there is not one canonical use of "race" in scientific practice but a patchwork of different uses in different contexts, there is little hope that philosophers will identify one fundamental meaning of race $_{\text {scientific }}$. It is therefore highly plausible to extend deflationism from race ordinary $_{\text {versus }}$

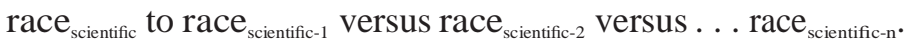

If we turn our attention to commonsense uses of "race," the situation is prima facie even worse. Empirical studies of the commonsense concept of race in the United States reveal not only a large number of possible criteria (e.g., essences, phenotypes, ancestry, social context, self-identification) but also an impressive amount of disagreement regarding these criteria (Glasgow et al. 2009; Morning 2011). Given this diversity, one may argue that we should also distinguish between different concepts race ordinary-1$_{1}$, race $_{\text {ordinary-2}}, \ldots$, race $_{\text {ordinary-n }}$ that are involved in ordinary racial discourse and that have often contradicting consequences for the ontological status of race. Note that this problem of different candidate meanings of "race" does not disappear if we follow contemporary realists (e.g., Spencer 2014a) and antirealists (e.g., Glasgow 2009) in focusing exclusively on "race" in the United States and exclude problems of the global variability of the meaning of "race" (Daniel 2010).

Given that Glasgow's own empirical work (Glasgow, Shulman, and Covarrubias 2009) provides detailed evidence of heterogeneous uses of "race" in the United States, he is well aware of the possibility of multiple candidate 
meanings. Still, he rejects the suggestion that "race" is compatible with mul-

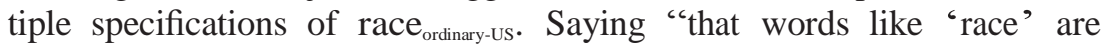
ambig- uous . . . would be saying that we are simply babbling past one another when we talk about race, rather than having a linguistically sensible conversation. This is implausible" (Glasgow 2009, 75). Of course, it is implausible that "race" is a homonym with unrelated meanings that happen to have the same linguistic form (e.g., river bank vs. financial bank). However, Glasgow's own data seem to support the idea that "race" is polysemous in the sense of hav- ing related meanings that may be understood on a continuum between pure ambiguity and vagueness (Tuggy 1993). The assumption that "race" in the United States comes with polysemous ambiguity suggests the following an- swers to Glasgow's objection. First, polysemy can be contextually resolved and therefore allow "sensible conversation" in sufficiently specific contexts of application (e.g., at home, in school, while filling out an official question- naire). Second, contextually unresolved polysemy does not imply a complete breakdown of communication given a sufficient extensional and/or inten- sional overlap of polysemously related candidate meanings. Instead, race talk in the United States may often involve a good deal of "talking past one another" without reducing to meaningless babbling.

While Glasgow's negative argument against multiple specifications of race $_{\text {ordinary-us }}$ seems too hasty, he also provides positive arguments for his

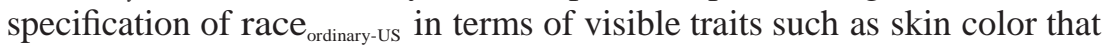
refer to meaningful biological kinds. For example, Glasgow employs thought experiments such as the global application of a "chemical agent that causes our bodies to take on a relatively uniform appearance" (Glasgow $2010,63)$. Glasgow suggests that this chemical agent would make race ordinary-us $_{\text {s }}$ inapplicable, therefore showing that visible traits are of crucial relevance for race $_{\text {ordinary-us. }}$ Given that groups of humans that share visible traits such as skin color do not constitute biologically meaningful groups, Glasgow concludes that we should be antirealists about race.

Note that deflationists (contrary to racial realists) do not have to deny that Glasgow provides a permissible specification of race $_{\text {ordinary-us, }}$, but they will deny that he provides the only permissible specification. To illustrate the possibility of a different specification, consider Spencer's (2014a) recent realist proposal that relies on the idea that the US meaning of "race" corresponds to the US Census racial discourse. Spencer not only points out that the US Census racial discourse does not require visible traits in the sense of Glasgow but also convincingly argues that "race" in the sense of the US Census racial discourse is relevant in the sense that "Americans are familiar with Census racial groups not only from filling out the federal census but because the Census racial scheme permeates just about every important facet of American life" ð2014a, 1027p. 
While I agree that the example of the US Census racial discourse challenges the claim that we have to understand race $_{\text {ordinary-us }}$ in the sense of Glasgow's specification, Spencer attempts to go a step further by defending a racial realism that faces the same problem of having to exclude alternative

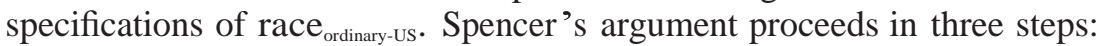
First, he suggests that the "U.S. meaning of 'race' is the national meaning of

"race' in the U.S." Second, he argues that the national meaning of "race" corresponds to the US Census racial discourse. Third, he argues that "race" in this sense is "rigidly designating . . . the partition at the $\mathrm{K}=5$ level of human population structure" ð2014a, 1025p.

This implies that Spencer's realist strategy faces the same challenge as Glasgow's antirealism in the sense that it also has to exclude alternative candidate meanings of race $_{\text {ordinary-us }}$ that would lead to different ontological conclusions. Given the focus on the commonsense concept of race, this strategy requires a rejection not only of Glasgow's proposal but also of specifications of race ordinary-us $_{\text {in }}$ terms of nonbiological social kinds. Even if we accept many of Spencer's premises (e.g., the meaning of "race" is its referent, and the extension of "race" in the United States is American Indians, Asians, Blacks, Pacific Islanders, and Whites), we could still think of the referents as racialized groups that are socially positioned as subordinate or privileged in the sense of Haslanger (2012) instead of Spencer's genetic clusters.

Spencer attempts to avoid the problem of different candidate meanings

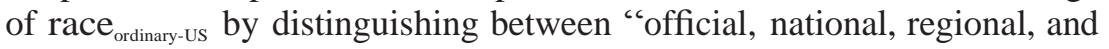
ethnic" meanings of a term. Furthermore, he illustrates this distinction with an analogy to languages in Belize and distinguishes between English as the national language, Belize Kriol as the ethnic language, and Spanish as a regional language. Spencer uses this distinction to argue that philosophical debates should focus on the national meaning of "race" and specifies this meaning in terms of US Census racial discourse. This strategy allows Spencer to exclude alternative candidate meanings as irrelevant for philosophical debates about the referent of "race" in the United States. Indeed, Glasgow's account may specify some "regional" or "ethnic" meanings

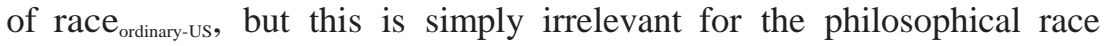
debate that is concerned with the national meaning of "race" in the United States. The same consideration applies to the variety of specifications of "race" in terms of race $_{\text {scientific-1 }}$, race $_{\text {scientific-2 }}, \ldots$, race $_{\text {scientific-n. }}$. In other words, "race" may be polysemous, but if philosophers disagree on the reality of race $_{\text {ordinary-us, }}$, only the national meaning of "race" matters.

Even if we accept this distinction among official, national, regional, and ethnic meanings of a term, however, we would still need evidence that there is exactly one national meaning of "race" that should be considered the only 
relevant candidate meaning for philosophical debates about race ordinary-us. $_{\text {. In }}$ fact, there are two issues here. First, Spencer would have to show that there is a national meaning of "race" that is the "widest used meaning in a nation." For example, this would exclude the alternative hypothesis that most uses of "race" in the United States involve contextually unresolved polysemy and therefore remain compatible with a range of candidate meanings. Second, Spencer would have to argue that the wide use of the national meaning makes it the only relevant candidate meaning for philosophical debates about the referent of "race" in the United States. In contrast, a social constructionist may argue that a meaning that involves social hierarchy (e.g., in the sense of Haslanger 2012) should be considered more (or equally) relevant because of its impact on American society no matter whether sociolinguistic research reveals it as the "most widely used." In other words, Spencer would have to show that the most widely used meaning of a term constitutes the only relevant candidate meaning for a philosophical debate about its referent.

Spencer's example of Belizean languages is of little help here because it actually illustrates the possibility of a different conclusion. Imagine a dispute between three parties about the referent of "language of Belize." P1 claims that "language of Belize" refers to English because it is the de facto national language that is used in official contexts and spoken by the majority of the population. P2 objects that only a small minority of Belizians speak English as their first language and that English is also not the only language that is spoken by the majority of the population. She suggests that Belize Kriol is the "language of Belize" as it is not only the ethnic language of Belize but also the lingua franca in large parts of the country. P3 insists that demographic change in Belize has recently made Spanish the "language of Belize," as migration from other Mesoamerican countries has made Spanish the most common native language in Belize. I assume that it would be largely uncontroversial that this dispute among P1, P2, and P3 is merely verbal in the sense that there is not only one correct way to specify the ambiguous term "language of Belize." Of course, the term "language of Belize" may have a specific meaning in a sufficiently well defined context, but any general and context-independent debate about the referent of "lan- guage of Belize" will end up in a nonsubstantive verbal dispute.

The example of "language of Belize" nicely illustrates that at least some concepts are too ambiguous to identify exactly one prior candidate meaning. Without a clear argument for exactly one fundamental candidate meaning of "race" in the United States, it is plausible to interpret the debate about race in analogy to "language of Belize." For example, P1 (e.g., Spencer 2014a) argues that the meaning of "race" corresponds to the US Census racial discourse. P2 (e.g., Glasgow 2009) suggests that "race" requires visible traits that 
undermine an identification with meaningful biological kinds. P3 (e.g., Haslanger 2012) suggests that "race" refers to racialized groups that are socially positioned as subordinate or privileged along some dimension. And so on. Again, each of the proposals may identify the relevant meaning of "race" in a sufficiently specified context, but a general metaphysical debate about the

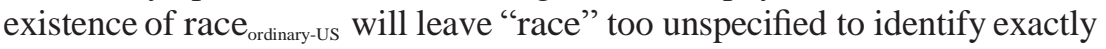
one permissible candidate meaning.

3.3. Metaphysics and Philosophy of Race. Let us take stock. I have argued that "race" is too ambiguous and vague to support a general metaphysical debate about the question whether human races exist. At the very least, we have to distinguish between scientific and commonsense concepts of race. However, there is arguably not only one scientific or commonsense concept of race, either. Even if we focus more specifically on the question

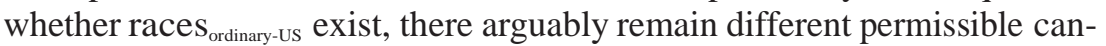
didate meanings that imply different ontologies of race. Philosophers should therefore not pretend to have a metaphysically deep solution to the question whether races exist but simply acknowledge that the answer to the question whether races exist depends on how "race" is specified.

While all of this is bad news for metaphysicians of race, it clearly does not undermine philosophy of race in a more general sense. Recall that I take metaphysicians of race to be committed to the ideal of a fundamental ontology of race. A rejection of this ideal is entirely compatible with other projects in philosophy of race, such as Haslanger's "ameliorative project . . . that raise[s] questions about how we should understand race" (2012, 387). In fact, the ameliorative project can provide an important alternative to metaphysical debates and shift our attention to epistemological and social aspects that "are not merely overlooked but systematically ignored and even foreclosed" (Gannett 2010, 363).

Furthermore, the claim that there is not one fundamental ontology of race is clearly compatible with other positions in philosophy of race that raise similar methodological worries. On the one hand, philosophers have questioned assumptions about natural kinds that underlie metaphysical debates about race (Kitcher 2007; Gannett 2010). While this strategy can also lead to a deflationist conclusion, I argue in the next section that we do not need to make any assumptions about natural kinds in order to motivate deflationism. On the other hand, worries about the metaphysics of race have also been raised on the basis of a general rejection of "arguments from reference" (Mallon et al. 2009; see also Mallon 2006). In contrast to this objection, my argument is fully compatible with the assumption that "arguments from reference" are usually legitimate and only fail in the context of ambiguous terms such as "race" (or "language of Belize," "schizophrenia," etc.). 
4. Metaontological Deflationism. I have argued that the ontology of race is underdetermined by empirical and nonempirical evidence. Even if we combine our empirical knowledge about human biological diversity with philosophical tools such as theories of reference or conceptual analysis, we still end up with a plurality of specifications of "race" that have contradicting ontological implications. At the end of the previous section, I suggested that this situation leads to a deflationist position regarding metaphysical debates about the existence of human races. Clearly, this step from underdetermination to deflationism is not trivial and requires further consideration.

The need for a closer look at deflationism becomes apparent when my proposal is compared with general variants of metaontological deflationism. For example, one prominent controversy in contemporary ontology is concerned with the question of at what point two objects compose a new object. To illustrate this controversy, imagine a universe with three elementary particles $(\mathrm{x} 1, \mathrm{x} 2, \mathrm{x} 3)$ and the question of how many objects exist in this universe (cf. Putnam 1987). Ontologists who reject the existence of composed objects will insist on only three objects (x1, x2, x3), while ontologists who accept the existence of composed objects will assume up to seven objects $(x 1, x 2, x 3, x 1+x 2, x 1+3, x 2+3, x 1+x 2+x 3)$. Metaontological deflationists reject this debate by arguing that there are different but equally correct ways of talking about the existence of objects. The choice of an ontology not only is underdetermined by the available evidence but ultimately depends on how we choose to talk about the existence of objects. The similarity between this general metaontological deflationism and my discussion of the ontology of race seems apparent: the choice of a racial ontology not only is underdetermined by the available evidence but ultimately depends on how we choose to talk about the existence of races.

Hirsch (2011) develops a more careful defense of metaontological deflationism and offers a general account of nonsubstantive verbal disputes. According to Hirsch, a dispute is verbal if "each side can plausibly interpret the other side as speaking a language in which the latter's asserted sentences are true" $(2007,231)$. In the case of a universe with three elementary particles, one philosopher may assume the existence of three objects $(\mathrm{x} 1, \mathrm{x} 2$, $\mathrm{x} 3$ ) while another assumes the existence of seven objects (x1, x2, x3, x1 + x2, $\mathrm{x} 1+3, \mathrm{x} 2+3, \mathrm{x} 1+\mathrm{x} 2+\mathrm{x} 3)$. However, both philosophers can interpret the other side as speaking the truth in their own language by recognizing that there are different ways of talking about the existence of objects. As soon as both philosophers realize the availability of different conceptual frameworks, there is no point in a further dispute about the question of how many objects really exist, and remaining disagreements are nonsubstantive verbal disagreements.

Again, it seems attractive to extend this strategy to debates about the reality of races. Realists like Andreasen, Edwards, Leroi, Sesardic, and Spen- 
cer can interpret antirealists as speaking the truth in a language in which "race" refers to subspecies, populations with visible traits that mark relevant biological differences, populations with cognitive differences, and so on. Antirealists like Glasgow, Lewontin, Hochman, Maglo, and Zack can interpret realists as speaking the truth in a language in which "race" refers to genetic clusters, patterns of mating, clades, and so on. By realizing that each side speaks the truth in its own language, we are left without a substantive factual disagreement; only a merely verbal disagreement about the use of "race" remains.

4.1. From Metaphysical Disagreement to Metametaphysical Disagreement? Although it is attractive to present my argument in the context of a general metaphysical deflationism, this strategy also illustrates the risk of challenging the metaphysics of race on the basis of an equally controversial metametaphysics of race. This worry seems especially pressing in the context of the first type of underdetermination, which is based on the interest dependency of biological ontologies. My presentation of this type of underdetermination largely followed Winther and Kaplan, who consider themselves presenting a story about "different ways that ontologies are (co-) created and (co-)constructed (Goodman 1978; Hacking 2002, 2007) [and require the excavation of ] ontological assumptions (Kuhn [1962] 1970) situated in distinct (scientific) discourses (Foucault [1969] 1972)" (Winther and Kaplan 2013, 57). In other words, Winther and Kaplan explicitly endorse a general deflationism that is rejected by many contemporary metaphysicians who insist that a satisfying "realist picture requires the "ready made world' Goodman (1987) ridiculed" (Sider 2012, 65).

This contrast clearly illustrates the worry that my rejection of the metaphysics of race will lead to an equally controversial metametaphysics of race. Instead of getting closer to a solution of current controversies, we would therefore only shift the disagreement to a more abstract meta-level. Still, there may be room for compromise. One possible strategy is based on the observation that many ontological realists restrict their realism to debates about "fundamental ontologies" and accept "imperfect jointcarving" (Sider 2012, 129) in the so-called special sciences. For example, consider metaphysical debates about issues such as the existence of composed or vague objects. While a rejection of composed or vague objects implies that there are no biological objects, biologists will continue to use ontologies that include various composed and vague objects. In other words, a meta- physical realist may accept the interest dependency of "non-fundamental" ontologies of the "special sciences" and restrict her realism to fundamental philosophical ontologies (cf. Varzi 2011).

4.2. A Metaphysically Moderate Deflationism. While there may be some room for compromise regarding the interest dependency of biological 
ontologies, there is another and more direct way of making deflationist accounts of the metaphysics of race independent of general metametaphysical controversies. Even a maximally ambitious ontological realism in biology will remain entirely compatible with a second type of underdetermination that is concerned with the identification of biological kinds and races. To illustrate this, let us assume exactly one fundamental biological ontology that "carves nature at its joints" and leaves no role for contingent explanatory interests. Furthermore, recall my discussion of various concepts of race (18 ) in section 3.1. Arguably, even this ambitious ontological realism would not resolve the problem of various candidate meanings of "race," as it would not answer the question whether we should specify "race" in the sense of concepts $1-8$.

This point becomes clearer in light of the contemporary literature about verbal disputes (e.g., Jenkins 2013). Even philosophers who endorse a strong ontological realism accept that some disputes are nonsubstantive. For example, Sider $(2012,46)$ presents a highly ambitious metaphysical program but still allows nonsubstantive disputes, if an expression has multiple equally joint-carving candidate meanings. In other words, while Sider insists on the idea that concepts "carve nature at its joints" in some objective interest-independent sense, he still acknowledges that a dispute can be nonsubstantive if an expression E (e.g., "race") has multiple equally joint-carving candidate meanings $m_{1}-m_{n}$. Sider (2012) therefore summarizes his account of nonsubstantive disputes as follows:

$\begin{array}{lll} & \mathrm{m}_{1} & \text { no candidate carves at the joints } \\ \mathrm{m} \quad \mathrm{m}_{2} & \text { better than the rest; the } \\ \mathrm{m}_{3} & \text { question's answer turns on } \\ \mathrm{m}_{4} & \text { which candidate is adopted } \\ \mathrm{m}_{5} & \end{array}$

Sider's proposal illustrates that even the most enthusiastic metaphysician can endorse a deflationist account of the metaphysics of race. For example, the discussed race concepts $1-4$ can be interpreted as equally joint-carving candidates $\mathrm{m}_{1}, \mathrm{~m}_{2}, \mathrm{~m}_{3}$, and $\mathrm{m}_{4}$. Or, on a more general level, even enthusiastic metaphysicans can accept that there are multiple objective ways of distinguishing between populations below the species level. Some of these populations will be found only in nonhuman species with a more substantial history of reproductive isolation, while others are also found in Homo sapiens. In this situation, we will end up with multiple joint-carving candidate meanings for "race" that have different implications for the question whether human races exist. Furthermore, Sider also allows that we may pick a "non-jointcarving" candidate meaning over a "joint-carving" candidate meaning if the "joint-carving meaning [does not satisfy] enough of the 'core meaning' that is collectively associated with" a term (Sider 2012, 48). Arguably, this also 
leaves the door open for an identification of races with entities in the sense of concept $5,6,7$, or 8 . In other words, even passionate metaphysicians can accept that the new metaphysics of race is a bad idea and engages in a nonsubstantive dispute.

5. Conclusion. I have argued that we should endorse a deflationist account of the "new metaphysics of race" and reject debates about a supposedly fundamental ontology of race. However, this does not mean that we should reject philosophy of race in general. On the contrary, there clearly remain pressing questions about our classifications of human diversity and our conceptual choices regarding "race." Even if we give up on metaphysics of race, we still face the complex challenge of integrating our empirical knowledge about human diversity with the epistemic and social interests that shape our classifications. However, we should address this challenge by making our normative commitments explicit instead of masking them through a methodologically dubious metaphysics of race.

A discussion of classifications of human diversity may lead to a debate that is superficially similar to the debate between racial realism and racial antirealism. For example, a conservationist may argue that we should stick with the concept of race at least in some scientific contexts because it is epistemically fruitful and may also be of social importance in some biomedical contexts (e.g., Hacking 2005). ${ }^{5}$ An eliminativist may respond that scientists do not need a concept of race to distinguish between diverse populations in specific research contexts. Furthermore, she may argue that a continued use of racial distinctions is not only unnecessary but ultimately harmful as it will create misuse and misunderstandings in science communication. At least some of the proposals for race concepts 1-8 may resurface in this metaphysically shallow debate about human classification, and at least some philosophers will point out that they never meant to engage in a metaphysically ambitious debate. For example, Pigliucci and Kaplan's account of races as ecotypes explicitly acknowledges that races "can be defined and picked out in a number of ways" $(2003,1163)$ and appeals to pragmatic considerations. Furthermore, Hochman (2014) distinguishes between a "strong" realism that insists on subspecies and a "weak" realism that relies on largely uncontroversial facts about human diversity. Hochman argues that his disagreement with weak realists is semantic and may also accept that it is ultimately normative. Even if positions such as concepts $1-8$ reappear in a

5. Note my terminological shift from "realism" vs. "antirealism" to "conservationism" vs. "eliminativism." While these labels are often used interchangeably, it may be helpful to limit the former to metaphysical debates and to use the latter for partly normative debates about the question whether we should conserve or eliminate a category. 
metaphysically shallow discussion about classifications of human diversity, however, we will end up with a fundamentally different debate that assesses "the appropriateness of group categories of classification relative to the purposes of specific research programs, an assessment which on this pragmatic approach invites consideration of the social and political ramifications of drawing boundaries in one way rather than another" (Gannett 2010, 383).

\section{REFERENCES}

Alcoff, Linda. 2005. Visible Identities: Race, Gender, and the Self. Oxford: Oxford University Press.

American Anthropological Association. 1998. "Statement on Race.” http://www.aaanet.org/stmts /racepp.htm.

Andreasen, Robin. 1998. "A New Perspective on the Race Debate." British Journal for the Philosophy of Science 49 (2): 199-225.

— 2000. “Race: Biological Reality or Social Construct?” Philosophy of Science 67:653-66.

- 2007. "Biological Conceptions of Race.” In Philosophy of Biology, ed. Mohan Matthan and Christopher Stephans, 455-81. Amsterdam: Elsevier.

Appiah, Kwame. 2006. "How to Decide If Races Exist?" Proceedings of the Aristotelian Society 106:365-82.

Boxill, Bernard. 2004. "Why We Should Not Think of Ourselves as Divided by Race.” In Racism in Mind, ed. Michael Levine and Tamas Pataki, 209-24. Ithaca, NY: Cornell University Press.

Chalmers, David. 2009. “Ontological Anti-Realism.” In Metametaphysics: New Essays on the Foundations of Ontology, ed. David Chalmers et al., 77-129. Oxford: Oxford University Press.

Daniel, Reginald. 2010. Race and Multiraciality in Brazil and the United States. University Park: Penn State University Press.

Diaz-Leon, Esa. 2012. "Social Kinds, Conceptual Analysis, and the Operative Concept: A Reply to Haslanger." Humana Mente 22:57-74.

Edwards, A. W. F. 2003. “Human Genetic Diversity: Lewontin’s Fallacy.” BioEssays 25 (8): 798 801.

Feldman, Marcus, and Richard Lewontin. 2008. "Race, Ancestry, and Medicine." In Revisiting Race in a Genomic Age, ed. Barbara Koenig et al., 89-101. New Brunswick, NJ: Rutgers University Press.

Franklin-Hall, Laura. Forthcoming. "Natural Kinds as Categorical Bottlenecks.” Philosophical Studies.

Gannett, Lisa. 2010. “Questions Asked and Unasked.” Synthese 177 (3): 363-85.

Gissis, Snait. 2008. “When Is 'Race’ a Race? 1946-2003.” Studies in History and Philosophy of

Biological and Biomedical Sciences 39 (4): 437-50.

Glasgow, Joshua. 2003. "On the New Biology of Race.” Journal of Philosophy 100 (9): 456-74. - 2009. A Theory of Race. New York: Routledge.

- 2010. "Another Look at the Reality of Race, by Which I Mean Race-f." In New Waves in Metaphysics, ed. Allan Hazlett, 54-71, New York: Macmillan.

Glasgow, Joshua, Julie Shulman, and Enrique Covarrubias. 2009. "The Ordinary Conception of Race in the United States and Its Relation to Racial Attitudes." Journal of Cognition and Culture 9 (1-2): 15-38.

Hacking, Ian. 2005. “Why Race Still Matters.” Daedalus 134 (1): 102-16.

Hardimon, Michael. 2003. “The Ordinary Concept of Race.” Journal of Philosophy 100:437-55.

. 2012. "The Idea of a Scientific Concept of Race." Journal of Philosophical Research $37: 249-82$. 
Haslanger, Sally. 2010. “Language, Politics, and 'the Folk': Looking for 'the Meaning' of 'Race." " Monist 93:169-87.

2012. Resisting Reality. Oxford: Oxford University Press.

Hirsch, Eli. 2007. “Ontological Arguments: Interpretive Charity and Quantifier Variance." In Contemporary Debates in Metaphysics, ed. Theodore Sider, John Hawthorne, and Dean W. Zimmerman, 367-81. Oxford: Blackwell.

- 2011. Quantifier Variance and Realism: Essays in Metaontology. Oxford: Oxford University Press.

Hochman, Adam. 2013. “Against the New Racial Naturalism.” Journal of Philosophy 110 (7): 33151.

. 2014. "Unnaturalised Racial Naturalism." Studies in History and Philosophy of Biological and Biomedical Sciences 46:79-87.

Jenkins, Carrie. 2013. “Merely Verbal Disputes.” Erkenntnis 79 (1): 1-20.

Kalinowski, Steven. 2011. "The Computer Program STRUCTURE Does Not Reliably Identify the Main Genetic Clusters within Species: Simulations and Implications for Human Population Structure." Heredity 106:625-32.

Kaplan, Jonathan, and Rasmus Winther. 2012. "Prisoners of Abstraction? The Theory and Measure of Genetic Variation, and the Very Concept of 'Race." " Biological Theory 7:1-12.

Kitcher, Philip. 1999. “'Race, Ethnicity, Biology, Culture.” In Racism, ed. Leonard Harris, 87-117. New York: Humanity Books.

- 2007. "Does 'Race’ Have a Future?" Philosophy and Public Affairs 35 (4): 293-

317. Leroi, Armand. 2005. “A Family Tree in Every Gene.” Journal of Genetics 84 (1): 3-6.

Maglo, Koffi. 2011. “The Case against Biological Realism about Race: From Darwin to the Postgenomic Era." Perspectives on Science 19 (4): 361-90.

Mallon, Ron. 2006. " “Race’: Normative, Not Metaphysical or Semantic.” Ethics 116 (3): 525

51. Mallon, Ron, et al. 2009. “Against Arguments from Reference.” Philosophy and

Phenomenological Research 79 (2): 332-56.

Morning, Ann. 2011. The Nature of Race: How Scientists Think and Teach about Human Difference. Berkeley: University of California Press.

Pigliucci, Massimo. 2013. "What Are We to Make of the Concept of Race?" Studies in History and Philosophy of Biological and Biomedical Sciences 44 (3): 272-77.

Pigliucci, Massimo, and Jonathan Kaplan. 2003. "On the Concept of Biological Race and Its Applicability to Humans." Philosophy of Science 70 (5): 1161-72.

Putnam, Hilary.1987. "Truth and Convention.” Dialectica 41 (1-2): 69-77.

Root, Michael. 2003. "The Use of Race in Medicine as a Proxy for Genetic Differences." Philosophy of Science 70 (5): 1173-83.

Rosenberg, Noah, et al. 2002. "Genetic Structure of Human Populations.” Science 298 (5602): 2381-85.

Saul, Jennifer. 2006. "Philosophical Analysis and Social Kinds." Proceedings of the Aristotelian Society, Supp. 80 (1): 119-43.

Sesardic, Neven. 2010. "Race: A Social Destruction of a Biological Concept." Biology and Philosophy 25 (2): 143-62.

Sider, Ted. 2012. Writing the Book of the World. Oxford: Oxford University Press.

Slater, Matthew H. Forthcoming. "Natural Kindness." British Journal for the Philosophy of Science.

Spencer, Quayshawn. 2013. "Biological Theory and the Metaphysics of Race: A Reply to Kaplan and Winther." Biological Theory 8 (1): 114-20.

- 2014a. "A Radical Solution to the Race Problem." Philosophy of Science 81 (5): 1025-38.

- 2014b. "The Unnatural Racial Naturalism." Studies in History and Philosophy of Biological and Biomedical Sciences 46:38-43.

Templeton, Alan. 1998. "Human Races: A Genetic and Evolutionary Perspective." American Anthropologist 100 (3): 632-50.

. 2013. "Biological Races in Humans." Studies in History and Philosophy of Biological and Biomedical Sciences 44 (3): 262-71. 
Torres, Jada, and Rick Kittles. 2007. “The Relationship between 'Race’ and Genetics in Biomedical Research.” Current Hypertension Reports 9 (3): 196-201.

Tuggy, David. 1993. “Ambiguity, Polysemy, and Vagueness.” Cognitive Linguistics 4 (3): 273-90.

Varzi, Achille. 2011. "Boundaries, Conventions, and Realism." In Carving Nature at Its Joints, ed. Joseph K. Campbell, Michael O'Rourke, and Matthew H. Slater, 129-53. Cambridge, MA: MIT Press.

Winther, Rasmus, and Jonathan Kaplan. 2013. "Ontologies and Politics of Biogenomic 'Race." " Theoria 60 (136): 54-80.

Zack, Naomi. 2007. “Ethnicity, Race, and the Importance of Gender.” In Race or Ethnicity, ed. Jorge Gracia, 101-21. Ithaca, NY: Cornell University Press. 